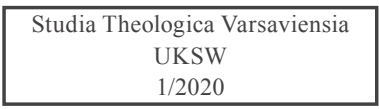

GrZegorz Łęcicki

\title{
IDEE KINEMATOGRAFICZNE U PROGU TRZECIEJ DEKADY XXI WIEKU
}

Czy przypisywane rabinowi Akibie ben Josefowi zdanie, , Wszytko już było" wolno odnieść do kinematografii u progu trzeciego dziesięciolecia XXI wieku? Jak na porównywalną z innymi dziedzinami kultury i twórczości artystycznej kino jest dość młodą sztuką; licząc od 1895 r., ma dopiero 125 lat. Choć jest starsze od radia i telewizji, to nawet $\mathrm{w}$ porównaniu z książką i prasą pozostaje młodym medium. Czy mając świadomość dość krótkiej historii filmu, wolno twierdzić, że we współczesnym czasie pojawiły się jakieś nowe idee w kinematografii światowej i polskiej? Niniejsze studium stanowić będzie próbę odpowiedzi na to pytanie. Podstawowym materiałem badawczym będą wybrane, charakterystyczne obrazy analizowane metodą indukcji fenomenologicznej.

\section{NOWY JĘZYK}

Film to przede wszystkim ruchomy obraz, ale obraz wzbogacony o dźwięk. Warstwa werbalna towarzysząca komunikatom ikonicznym stanowi istotny element języka filmu. Słowo bowiem to zarówno element akustyczny, jak i fundamentalny składnik dialogu1. Słowo jako nośnik idei odwołuje się do intelektu, myślenia abstrakcyjnego ${ }^{2}$,

${ }^{1}$ Cfr. J. Płażewski, Język filmu, Warszawa 2008, 354.

${ }^{2}$ Cfr. A. Zwoliński, Stowo w relacjach społecznych, Kraków 2003, 38-39. 


\section{CINEMATOGRAPHIC IDEAS AT THE TURN OF THE THIRD DECADE OF THE 21ST CENTURY}

Can the sentence attributed to Rabbi Akiba ben Josef, ,Everything was already there', be applied to cinematography at the turn of the third decade of the $21^{\text {st }}$ century? As for the cinema, which is comparable to other fields of culture and artistic creation, it is a fairly young art; it is only 125 years old starting back in 1895 . Although it is older than radio and television, it remains a young medium even when compared to books and the press. Being aware of the rather short history of film, is it possible to claim that in modern times some new ideas have entered the world and Polish cinematography? This study is an attempt to answer this question by means of basic research material selected, and characteristic images analysed with phenomenological induction.

\section{NEW LANGUAGE}

A film is basically a motion picture, enriched with sound. The verbal layer accompanying the iconic messages is an important element of the film language. For a word is both an acoustic element and a fundamental component of dialogue ${ }^{1}$. The word as a carrier of ideas refers to the intellect, and abstract thinking ${ }^{2}$, while the picture

${ }^{1}$ Cf. J. Płażewski, Język filmu, Warsaw 2008, 354.

2 Cf. A. Zwoliński, Stowo w relacjach społecznych, Kraków 2003, 38-39. 
natomiast obraz oddziałuje na emocje oraz wyobraźnię ${ }^{3}$. Analiza audialnego materiału, zawężonego do wypowiedzi bohaterów ${ }^{4}$ i dialogów pozwala na wskazanie kilku charakterystycznych zjawisk występujących w obrębie współczesnego języka filmu w zakresie komunikatów werbalnych.

Do charakterystycznych zjawisk werbalnej ekspresji współczesnego kina należy zwiększająca się liczba wulgaryzmów i przekleństw. Oczywiście wulgaryzmy mają swoje miejsce w języku, literaturze, filmie, ale epatowanie nimi we współczesnym kinie zarówno polskim, jak i zagranicznym przybrało niemal monstrualne rozmiary. Częste używanie przez bohaterów filmowych słów ordynarnych, brzydkich, nieprzyzwoitych nie tylko stanowi swoiste nawiązanie do codziennej rzeczywistości, lecz także ją kształtuje, szczególnie w zakresie oddziaływania na młodych widzów, których zmysł krytyczny nie jest jeszcze w pełni uformowany.

Obecność dużej liczby wulgaryzmów we współczesnym kinie powoduje nie tylko zaprzeczenie idei piękna jako podstawowego przesłania i sensu sztuki, również kinematograficznej, lecz także wyrabia fałszywe mechanizmy i złe nawyki, np. radzenia (czy raczej nieradzenia) sobie ze stresem, sposobu okazywania lekceważenia i obrażania kogoś oraz zwiększania siły krytykowania. Wulgaryzmy stanowią swoisty probierz świadczący o liberalizacji norm obyczajowych, a także o coraz mocniejszym nurcie neobarbarzyńskiej antykultury we współczesnej cywilizacji ${ }^{5}$. Warto przypomnieć, że pojęcie wulgaryzm pochodzi od łacińskiego słowa vulgus oznaczającego pospólstwo ${ }^{6}$. Dawniej sztuka uwznioślała, miała dostarczać pozytywnych przeżyć estetycznych, stanowiła afirmację piękna i przejaw geniuszu twórców. Obecnie nurt pospolitości zdaje się dominować, czego przejawem są właśnie wulgaryzmy jako język

${ }^{3}$ Cfr. A. Zwoliński, Obraz w relacjach spotecznych, Kraków 2004, 180-181.

${ }^{4}$ Cfr. M. Hendrykowski, Język filmu, w: M. Hendrykowski, Stownik terminów filmowych, Poznań 1994, 130.

5 Cfr. W. Roszkowski, Roztrzaskane lustro. Upadek cywilizacji zachodniej, Kraków 2019, 459.

${ }^{6}$ Cfr. Vulgus, w: K. Kumaniecki, Stownik łacińsko-polski, Warszawa 1999, 463. 
influences emotions and imagination. ${ }^{3}$ The analysis of audible material, narrowed down to the characters' utterances and dialogues, ${ }^{4}$ and dialogues, makes it possible to point out several characteristic phenomena in the contemporary language of film in terms of verbal communication.

The characteristic phenomena of verbal expression of contemporary cinema include an increasing number of dirty language and curses. Of course, vulgarisms have their place in the language, literature and film, but shocking with them in contemporary cinema, both Polish and foreign, has taken on almost monstrous proportions. The film characters often use rude, dirty, and barnyard language, not only as a reference to everyday reality, but to shape it as well, especially in terms of influencing young audiences whose critical sense is not yet fully formed.

A large number of vulgarisms in contemporary cinema not only denies the idea of beauty as the basic message and meaning of art, including cinematography, but also develops false mechanisms and bad habits, e.g. dealing with stress (or rather not dealing with it), demonstrating disrespect and insulting someone and increasing the power of criticism. Vulgarisms are a kind of testimony to the liberalisation of moral norms, as well as to the growing trend of neobarbaric anti-culture in modern civilisation. ${ }^{5}$ It is worth recalling that the concept of vulgarism is derived from the Latin word vulgus, which means the populace ${ }^{6}$. In the past, the art was supposed to elevate, provide positive aesthetic experiences, it was an affirmation of beauty and a manifestation of artists' genius. Nowadays, the mainstream of commonness seems to dominate, which is manifested by vulgarisms as the language of the nation, of everyday life. Primitive audio-visual

${ }^{3}$ Cf. A. Zwoliński, Obraz w relacjach społecznych, Kraków 2004, 180-181.

${ }^{4}$ Cf. M. Hendrykowski, Język filmu, in: M. Hendrykowski, Stownik terminów filmowych, Poznań 1994, 130.

5 Cf. W. Roszkowski, Roztrzaskane lustro. Upadek cywilizacji zachodniej, Kraków 2019, 459.

${ }^{6}$ Cf. Vulgus, in: K. Kumaniecki, Stownik tacińsko-polski [Latin-Polish Dictionary], Warsaw 1999, 463. 
ludu, codzienności. Prymitywne audiowizualne komunikaty ludyczne mające tylko bawić i potrafiące jedynie szokować, a nie zachwycać, prowadzą do zatracenia nie tylko wrażliwości właściwej dawnej estetyce wypowiedzi, lecz także skutkują pozbawieniem sztuki jej wymiaru symbolicznego, moralnego, duchowego, integracyjnego?.

$\mathrm{Z}$ drugiej jednak strony należy zwrócić uwagę na to, że wulgaryzmy stanowią mocne podkreślenie istotnych cech charakterologicznych filmowych bohaterów, grup i środowisk. Przykładem może być film Mayday ${ }^{8}$, którego bohaterem jest bigamista, a więc mężczyzna wiodący naganne życie oparte na kłamstwie i oszustwie. Egzemplifikacją ordynarnego języka przestępców są m. in. filmy Patryka Vegi ${ }^{9}$. Zaprzeczeniem klasycznych ideałów piękna, i to nie tylko języka, są obrazy przedstawiające złe kobiety, których negatywny wizerunek został wzmocniony poprzez używanie przez nie odrażających wulgaryzmów ${ }^{10}$. Spośród filmów zagranicznych za rekordowy pod względem występujących w nim przekleństw i wulgaryzmów należy uznać obraz Wilk z Wall Street ${ }^{11}$.

Niekiedy lekceważona kwestia obecności wulgaryzmów w świecie współczesnej sztuki, również kinematograficznej, ma jednak istotne znaczenie jako komunikat medialny, mocno wpływający na zwyczajny, codzienny sposób wysławiania się. Nadmiar ordynarnych słów nie tylko świadczy o niskim poziomie kultury osobistej osób ich używających, lecz także o ubóstwie słownictwa, agresji, nieumiejętności opanowania negatywnych emocji.

Koniecznie w tym kontekście należy podkreślić, że język bohaterów filmowych należy do istotnych elementów zarówno niektórych gatunków filmowych, jak i seriali telewizyjnych ${ }^{12}$. Wystarczy przy-

\footnotetext{
${ }^{7}$ Cfr. G. Łęcicki, Media audiowizualne w nauczaniu Jana Pawła II, Warszawa 2013, 172-173.

${ }^{8}$ Cfr. Mayday, reż. S. Akina, 2019.

9 Cfr. Pitbull. Nowe porzadki, reż. P. Vega, 2016; Bad boy, reż. P. Vega, 2020.

${ }^{10}$ Cfr. Kobiety mafii, reż. P. Vega, 2018; Kobiety mafii 2, reż. P. Vega, 2019.

${ }^{11}$ Cfr. Wilk z Wall Street, reż. M. Scorsese, 2013.

${ }_{12}$ Cfr. Serial telewizyjny, w: Popularna encyklopedia mass mediów, red. J. Skrzypczak, Poznań 1999, 490.
} 
folk messages that are only meant to entertain and can only shock and not delight, not only lead to the loss of sensitivity inherent in the old aesthetics of expression, but also result in depriving art of its symbolic, moral, spiritual and integrative dimension. ${ }^{7}$

On the other hand, it should be pointed out that vulgarisms are a strong emphasis on the important characteristics of film characters, groups and environments. An example is the film Mayday, where the main character is a bigamist, a man leading a reprehensible life based on lies and deception. The rude, dirty language of criminals is manifested in Patrick Vega's films, among others ${ }^{9}$. The bad women, whose negative image is reinforced by their use of disgusting vulgarisms, are a denial of the classical ideals of beauty, and not only the language. ${ }^{10}$ Among the foreign movies, The Wolf of Wall Street should be considered a record-breaking one in terms of profanity and vulgarity. ${ }^{11}$

The issue of the presence of vulgarisms in the world of contemporary art that sometimes seems neglected, including cinematography, is, however, important as a medium, strongly influencing the ordinary, everyday way of expressing oneself. Excessive amounts of swear words not only testify to the low level of personal culture of those who use them, but also to the poverty of vocabulary, aggression and the inability to control negative emotions.

In this context, it is important to stress out that the language of film characters is one of the essential elements of both certain film genres and television shows and series. ${ }^{12}$ Let us recall the film saga about the

7 Cf. G. Łęcicki, Media audiowizualne w nauczaniu Jana Pawła II, Warsaw 2013, 172-173.

${ }^{8}$ Cf. Mayday, directed by S. Akina, 2019.

9 Cf. Pitbull. Nowe porzadki, directed by P. Vega, 2016; Bad boy, directed by P. Vega, 2020.

${ }^{10}$ Cf. Kobiety mafii, directed by P. Vega, 2018; Kobiety mafii 2, directed by P. Vega, 2019.

${ }^{11}$ Cf. The Wolf of Wall Street, directed by M. Scorsese, 2013.

${ }^{12}$ Cf. Serial telewizyjny [TV show], in: Popularna encyklopedia mass mediów, ed. J. Skrzypczak, Poznań 1999, 490. 
pomnieć filmową sagę o Kargulach i Pawlakach ${ }^{13}$, których zabawne powiedzonka weszły do języka potocznego i stały się elementem kultury popularnej, podobnie jak błyskotliwe stwierdzenia oraz dowcipne riposty porucznika Borewicza ze znanego serialu kryminalnego $^{14}$. Za najbardziej udane i uzasadnione użycie wulgaryzmu jako elementu komicznego wolno uznać przypadkowo wypowiedziane hasło werbalne sprowadzające windę wiodącą z podziemnego świata na powierzchnię w Seksmisji ${ }^{15}$. Wyjątkowość sformułowania nie raziła, bo była przypadkiem pojedynczym i należała do rzadkości. Kontekst zaś powodował, że popularny wulgaryzm śmieszył, a nie oburzał. Należy przypomnieć, że PRL-owska cenzura nie dopuszczała do zbytniej wulgaryzacji języka w przekazach medialnych, a państwo starało się promować kulturę wyższą także poprzez eliminację sformułowań ordynarnych, co zmuszało twórców do poszukiwania swoistych synonimów i tworzenia języka odbiegającego od codziennych realiów, co zostało wyśmiane przez Stanisława Bareję w uznawanej za kultową komedii Mis ${ }^{16}$, której jedna z sekwencji dotyczyła oficera milicji, zwanego Wujkiem Dobra Rada, radzącego młodzieży jak reagować na używanie przez rówieśników brzydkich wyrazów i sformułowań, takich jak „motyla noga”, „,kurcze pióro” ${ }^{17}$.

Oprócz zwrócenia uwagi na postępująca wulgaryzację języka filmu poprzez nasycenie wypowiedzi i dialogów słowami ordynarnymi należy jeszcze podkreślić zmianę formy wypowiedzi, która

${ }^{13}$ Cfr. Sami swoi, reż. S. Chęciński, 1967 ; Nie ma mocnych, reż. S. Chęciński, 1974; Kochaj albo rzuć, reż. S. Chęciński, 1977. Cfr. D. Koźlenko, Sami swoi. Za kulisami komedii wszech czasów, Warszawa 2016, 79-80, 83-84, 123, 129, 141, 149, 156, 188, 192-193, 208, 248.

${ }^{14}$ Cfr. 07 zgłoś się, reż. K. Szmagier i in., 1979-1987. Cfr. P. K. Piotrowski, 07 zgłasza się. Opowieść o serialu, Warszawa 2013, 125, 135, 139, 167, 172-173, 176, 188, 199-200, 220, 230, 246.

${ }_{15}$ Cfr. Seksmisja, reż. J. Machulski, 1983.

${ }^{16}$ Cfr. Miś, reż. S. Bareja, 1980. Cfr. M. Łuczak, Miś czyli świat wedlug Barei, Warszawa bdw, 129.

${ }^{17}$ Cfr. M. Replewicz, Oczko się odlepiło temu misiu... Biografia Stanisława Barei, Warszawa 2015, 222; Stanisław Bareja alternatywnie, Poznań 2019, 236-237. 
Kargul and the Pawlak families ${ }^{13}$, whose funny sayings entered the common language and became part of popular culture, as well as the brilliant statements and witty retorts of Lieutenant Borewicz from the well-known crime series ${ }^{14}$. The most successful and justified use of vulgarism as a comic element can be considered to be the accidentally Sexmission [Polish: Seksmisja $]^{15}$. The uniqueness of the phrase do not seem to be striking, as it is a single case and rare. The context itself made popular vulgarism funny, not outrageous. It should be recalled that the censorship of the People's Republic of Poland did not allow for too much vulgarisation of language in media messages, and the state tried to promote higher culture also by eliminating rude expressions, which forced authors to search for specific synonyms and to create a language that differed from everyday reality, which was ridiculed by Stanislaw Bareja in the cult comedy Teddy Bear [Polish: Miś' ${ }^{16}$, The censorship of the People's Republic of Poland did not allow for excessive vulgarisation of language in media messages, and the state tried to promote a higher culture also by eliminating rude formulations, which forced authors to search for specific synonyms and to create a language that differed from everyday reality, which was ridiculed by Stanislaw Bareja in the cult comedy Teddy Bear, one of the sequences of which concerned a militia officer, called Uncle Good Advice, advising young people how to react to the use of ugly

${ }^{13}$ Cf. Sami swoi [translated as All Friends Here or Our Folks], directed by S. Chęciński, 1967 ; Nie ma mocnych [translated as Take It Easy], directed by S. Chęciński, 1974; Kochaj albo rzuć [translated as Love or Leave], directed by S. Chęciński, 1977. Cf. D. Koźlenko, Sami swoi. Za kulisami komedii wszech czasów, Warsaw 2016, 79-80, 83-84, 123, 129, 141, 149, 156, 188, 192-193, 208, 248.

${ }^{14}$ Cf. 07 zgloś się, directed by K. Szmagier i in., 1979-1987. Cf. P. K. Piotrowski, 07 zglasza się. Opowieść o serialu, Warsaw 2013, 125, 135, 139, 167, 172-173, 176, 188, 199-200, 220, 230, 246.

15 Cf. Seksmisja [translated as Sexmission], directed by J. Machulski, 1983.

${ }^{16}$ Cf. Miś [translated as Teddy Bear], directed by S. Bareja, 1980. Cf. M. Łuczak, Miś czyli świat wedtug Barei, Warsaw bdw, 129. 
odbiega od klasycznego modelu akcentującego poprawą dykcję oraz wyrazistość, a skłaniającą się bardziej do przenoszenia na ekran mowy popularnej, niedbałej o estetykę, czasem nawet bełkotliwej, niewyraźnej, utrudniającej percepcję audialną. Maniera ta, dostrzegalna szczególnie w polskich produkcjach współczesnych, deprecjonuje znaczenie języka jako podstawowego elementu i dobra kultury narodowej.

\section{MIT TOLERANCJI}

Do cech charakterystycznych współczesnej kinematografii zaliczyć można propagowanie stereotypu totalnej tolerancji wobec zachowań dawniej powszechnie uznawanych za naganne. Najwyraźniej jest to dostrzegalne na przykładzie odniesienia do osób homoseksualnych. Oprócz zagranicznych obrazów przedstawiających związki homoseksualne, jak np. film Tajemnice Brokeback Mountain ${ }^{18}$, skłonności pedofilskie, jak np. Lolita ${ }^{19}$, relacje lesbijskie Życie Adeli ${ }^{20}$, prostytucję homoseksualną, jak np. Moje własne Idaho ${ }^{21}$ w tym także wśród nastolatków, co zostało pokazane w czeskim filmie Mandragora ${ }^{22}$ wyliczyć można również polskie obrazy wpisujące się w nurt prezentujący bohaterów nieheteroseksualnych. Należy zauważyć zjawisko niemal permanentnej obecności postaci homoseksualnych we współczesnych polskich komediach romantycznych i obyczajowych. Obraz postaci homoseksualnych nosi cechy ustalonego stereotypu, gdyż bohaterowie ci są najczęściej prezentowani w niezwykle pozytywnym świetle, jako empatyczni, uczynni, tolerancyjni, pomocni, czuli, wrażliwi, delikatni przyjaciele innych ekranowych postaci. Wśród polskich filmów tak pokazujących homoseksualistów wyliczyć można

${ }_{18}$ Cfr. Tajemnice Brokeback Mountain, reż. A. Lee, 2005.

19 Cfr. Lolita, reż. A. Lyne, 1997.

${ }^{20}$ Cfr. Życie Adeli, reż. A. Kechiche, 2013.

${ }^{21}$ Cfr. Moje własne Idaho, reż. G. Van Sant, 1991.

${ }^{22}$ Cfr. Mandragora, reż. W. Grodecki, 1997. 
words and phrases by their peers, such as „Stone me!”, “Shoot!” or „Sugar!” ${ }^{17}$.

Apart from drawing attention to the progressive vulgarisation of the film language by saturating utterances and dialogues with rude words, one should also emphasize the change in the form of expression, which departs considerably from the classical model emphasising correct diction and expressiveness, and leansing more towards the transfer of popular speech onto the screen, which is not aesthetically pleasing, sometimes even gibberish, blurred, and impeding audible perception. This manner, which is particularly noticeable in Polish contemporary productions, depreciates the importance of language as a basic element and a national cultural asset.

\section{MYTH OF TOLERANCE}

Characteristic features of contemporary cinematography include the promotion of the stereotype of absolute tolerance towards behaviour that used to be commonly regarded as reprehensible. This is most apparent when we refer to the homosexuals. Apart from foreign movies depicting homosexual relationships, such as Brokeback Mountain ${ }^{18}$, paedophile tendencies, such as Lolita ${ }^{19}$, lesbian relations in Blue Is The Warmest Colour ${ }^{20}$, homosexual prostitution, such as My Own Private Idaho ${ }^{21}$, also among teenagers, as shown in the Czech film Mandragora ${ }^{22}$, we can list Polish pictures that are part of the mainstream presenting non-heterosexual characters. The phenomenon of the nearly permanent presence of homosexual characters in contemporary Polish romantic and moral comedies should be noted. The image of homosexual characters has the features

17 Cf. M. Replewicz, Oczko się odlepiło temu misiu... Biografia Stanisława Barei, Warsaw 2015, 222; Stanisław Bareja alternatywnie, Poznań 2019, 236-237.

18 Cf. Brokeback Mountain, directed by A. Lee, 2005.

19 Cf. Lolita, directed by A. Lyne, 1997.

20 Cf. Blue Is The Warmest Colour, directed by A. Kechiche, 2013.

21 Cf. My Own Private Idaho, directed by G. Van Sant, 1991.

22 Cf. Mandragora, directed by W. Grodecki, 1997. 
następujące obrazy: Mała wielka mitość ${ }^{23}$, Listy do $M^{24}$, Planeta singli $3^{25}$. Rzadszym motywem aktualnego polskiego kina bywają skłonności oraz związki lesbijskie. Pokazano je w filmach obyczajowych, np. Nina ${ }^{26}$, Plan $B^{27}$ oraz w komediach Idealny chtopak dla mojej dziewczyny ${ }^{28}$, Misz masz czyli kogel mogel $3^{29}$, Futro z misia ${ }^{30}$. Specyficznym rodzajem dramatów obyczajowych odnoszących się do problematyki homoseksualnej są obrazy ukazujące duchownych i polityków uwikłanych w takie relacje, co zaprezentowano w obrazie $W$ imię... ${ }^{31}$ oraz w Polityce ${ }^{32}$. Niekiedy zestawienie postaci homoseksualnej z osobami heteroseksualnymi ma na celu podkreślenie ich uprzedzeń, nietolerancji, agresji, obskurantyzmu, niewierności, dwulicowości, obłudy, zakłamania, co ostatnio dobitnie zaakcentował obraz (Nie)znajomi ${ }^{33}$.

Przykładem świadczącym o pokazywaniu przekraczania kolejnych granic obyczajowego tabu stał się film przedstawiający seks byłego ucznia z nauczycielką szkoły katolickiej ${ }^{34}$ oraz obraz zawierający motywy orgiastyczne ${ }^{35}$.

\section{PRZEKRACZANIE BARIER}

Kino, od początku istnienia świadome sugestywnego oddziaływania na emocje, wykorzystywało pokazywanie dwóch najsilniejszych uczuć, a mianowicie miłości i strachu. Ewolucja w pokazywaniu

${ }^{23}$ Cfr. Mała wielka miłość, reż. Ł. Karwowski, 2008.

${ }^{24}$ Cfr. Listy do M, reż. M. Okorn, 2011.

${ }_{25}$ Cfr. Planeta singli 3, reż. S. Akina, M. Chaciński, 2019.

${ }^{26}$ Cfr. Nina, reż. O. Chajdas, 2018.

27 Cfr. Plan B, reż. K. Dębska, 2018.

${ }^{28}$ Cfr. Idealny chłopak dla mojej dziewczyny, reż. T. Konecki, 2009.

${ }^{29}$ Cfr. Misz masz czyli kogel mogel 3, reż. K. Piwowarski, 2019.

${ }^{30}$ Cfr. Futro z misia, reż. K. Anuszewski, M. Milowicz, 2019.

${ }^{31}$ Cfr. Wimię..., reż. M. Szumowska, 2013.

32 Cfr. Polityka, reż. P. Vega, 2019.

33 Cfr. (Nie)znajomi, reż. T. Śliwa, 2019.

${ }^{34}$ Cfr. Lejdis, reż. T. Konecki, 2008.

${ }^{35}$ Cfr. Ja teraz kłamię, reż. P. Borowski, 2019. 
of an established stereotype, mostly presented in an extremely positive light, as empathic, helpful, tolerant, helpful, sensitive, sensitive, and gentle friends of other film characters. Some Polish films showing homosexuals in this way include the following pictures: Mata wielka mitoś c $^{23}$, Listy do $\mathrm{M}^{24}$, and Planeta singli $3^{25}$. Lesbian inclinations and relationships are less common in contemporary Polish cinema. You can watch those in $\mathrm{Nina}^{26}$, or Plan $\mathrm{B}^{27}$, and in comedies Idealny chtopak dla mojej dziewczyny ${ }^{28}$, Misz masz czyli kogel mogel $3^{29}$, and Futro $z$ misia $^{30}$. A specific type of moral dramas relating to homosexual issues are those depicting clergy and politicians entangled in such relations, as presented in $W$ imię... ${ }^{31}$ and in Polityka $a^{32}$. Sometimes the juxtaposition of a homosexual person with heterosexual people is intended to highlight their prejudices, intolerance, aggression, obscurantism, unfaithfulness, double-sidedness, hypocrisy, or insults, which has recently been highlighted by (Nie)znajomi ${ }^{33}$.

An example illustrating the crossing of successive taboos is a film depicting a sexual relationship between a former student of a Catholic school with his teacher ${ }^{34}$ and a scene showing sex with orgiastic motifs. $^{35}$

23 Cf. Mała wielka miłość, directed by Ł. Karwowski, 2008.

24 Cf. Listy do M, directed by M. Okorn, 2011.

25 Cf. Planeta singli 3, directed by S. Akina, M. Chaciński, 2019.

26 Cf. Nina, directed by O. Chajdas, 2018.

27 Cf. Plan B, directed by K. Dębska, 2018.

28 Cf. Idealny chtopak dla mojej dziewczyny, directed by T. Konecki, 2009.

29 Cf. Misz masz czyli kogel mogel 3, directed by K. Piwowarski, 2019.

30 Cf. Futro z misia, directed by K. Anuszewski, M. Milowicz, 2019.

31 Cf. Wimię..., directed by M. Szumowska, 2013.

32 Cf. Polityka, directed by P. Vega, 2019.

33 Cf. (Nie)znajomi, directed by T. Śliwa, 2019.

34 Cf. Lejdis, directed by T. Konecki, 2008.

35 Cf. Ja teraz ktamię, directed by P. Borowski, 2019. 
nagości, seksu i coraz śmielszych scen erotycznych doprowadziła do niemal stałej ich obecności w kinematografii ${ }^{36}$. W ostatnim ćwierćwieczu XX w. w kręgu kultury zachodniej szokującym zjawiskiem stały się filmy zapoczątkowane obrazem Emmanuelle ${ }^{37}$, afirmujące rozmaite formy swobodnego seksu, a także gwałtu. Kolejne przełamywanie barier oraz przekraczanie granic obyczajowego tabu związane było z ekranowymi przedstawieniami praktyk sadomasochistycznych i to zarówno przez kinematografię zachodnią ${ }^{38}$, jak i dalekowschodnią, głównie japońską. Ekranizacje skandalizujących powieści, np. Historia $\mathrm{O}^{39}, \mathrm{Obraz}^{40}$, a także produkcje japońskie, m. in. Flower and snake ${ }^{41}$, Rope cosmetology $y^{42}$ epatowały coraz silniejszymi bodźcami, czyli obrazami maltretowania, poniżania, torturowania kobiet oraz ukazywaniem rozmaitych form perwersyjnego seksu ${ }^{43}$. Motyw kobiety jako seksualnej niewolnicy pojawiał się później również w filmach amerykańskich, takich jak np. Dziewięć i pół tygodnia ${ }^{44}$ i Sekretarka ${ }^{45}$. Tematyka łącząca seks z przemocą, posłuszeństwem, dobrowolną kobiecą uległością wobec męskiej dominacji ponownie pojawiła się w połowie drugiej dekady XXI w. wraz z ekranizacjami niezwykle popularnych powieści erotycznych Pięćdziesiąt twarzy Greya ${ }^{46}$, Ciemniejsza strona Greya ${ }^{47}$, Nowe oblicze Greya ${ }^{48}$. Ekspresyjne i dosadne obrazy wyuzadanego seksu w sposób istotny wypaczają ideał miłości jako relacji mającej istotny wymiar psy-

${ }^{36}$ Cfr. A. Zwoliński, Obraz..., op. cit., 181.

37 Cfr. Emmanuelle, reż. J. Jaeckin, 1974.

${ }^{38}$ Cfr. J. Płażewski, Historia filmu francuskiego, Warszawa 2005, 352.

${ }^{39}$ Cfr. Historia O, reż. J. Jaeckin, 1975.

${ }^{40}$ Cfr. Obraz, reż. R. Metzger, 1975.

${ }^{41}$ Cfr. Flower and snake, reż. M. Konuma, 1974.

${ }^{42}$ Cfr. Rope cosmetology, reż. S. Nishimura, 1978.

${ }^{43}$ Cfr. J. Sharp, Za różową kurtyną. Historia japońskiego kina erotycznego, tł. J. Murczyńska, K. Klimek, G. Żuchowska, Warszawa-Kraków 2011, 290 - 291.

${ }^{44}$ Cfr. Dziewięć i pól tygodnia, reż. A. Lyne, 1986.

${ }^{45}$ Cfr. Sekretarka, reż. S. Shainberg, 2002.

${ }^{46}$ Cfr. Pięćdziesiąt twarzy Greya, reż. S. Taylor-Johnson, 2015.

${ }^{47}$ Cfr. Ciemniejsza strona Greya, reż. J. Foley, 2017.

${ }^{48}$ Cfr. Nowe oblicze Greya, reż. J. Foley, 2018. 


\section{CROSSING BARRIERS}

Since the beginning of its existence, the cinema, aware of its suggestive influence on emotions, has exploited the two strongest feelings, namely love and fear. The evolution in showing nakedness, sex and increasingly bold erotic scenes has led to their almost permanent presence in cinematography.$^{36}$ In the last quarter of the 20th century, films initiated with Emmanuelle $e^{37}$ became a shocking phenomenon of the Western culture, affirming various forms of free sex, as well as rape. Further breaking down barriers and crossing the boundaries of taboos related to screen productions depicting sadomasochistic practices, both by Western ${ }^{38}$ and Far Eastern cinematography, mainly Japanese. Screenings of scandalous novels, e.g. Story of $O^{39}$, The Image ${ }^{40}$, as well as Japanese productions, e.g. Flower and Snake ${ }^{41}$, Rope Cosmetology $y^{42}$ were stirring up stronger and stronger stimuli, i.e. images of mistreatment, humiliation, torturing women and showing various forms of perverse sex. ${ }^{43}$ The motif of a woman as a sexual slave also appears later in American pictures, such as Nine 1/2 Weeks $^{44}$ and Secretary ${ }^{45}$. The theme of combining sex with violence, obedience, voluntary female submissiveness to male domination reappeared in the middle of the second decade of the 21st century with screenings of the extremely popular erotic novels Fifty

${ }^{36}$ Cf. A. Zwoliński, Obraz..., op. cit., 181.

37 Cf. Emmanuelle, directed by J. Jaeckin, 1974.

${ }_{38}$ Cf. J. Płażewski, Historia filmu francuskiego, Warsaw 2005, 352.

${ }^{39}$ Cf. Story of $O$, directed by J. Jaeckin, 1975.

${ }^{40}$ Cf. The Image, directed by R. Metzger, 1975.

${ }^{41}$ Cf. Flower and Snake, directed by M. Konuma, 1974.

${ }^{42}$ Cf. Rope Cosmetology, directed by S. Nishimura, 1978.

${ }^{43} \mathrm{Cf}$. J. Sharp, Za różowa kurtyną. Historia japońskiego kina erotycznego, transl. J. Murczyńska, K. Klimek, G. Żuchowska, Warsaw - Kraków 2011, 290-291.

${ }^{44}$ Cf. Nine 1/2 Weeks, directed by A. Lyne, 1986.

${ }^{45}$ Cf. Secretary, directed by S. Shainberg, 2002. 
chiczny i duchowy, wzajemnego oddania się, partnerstwa, zważania na pragnienia i emocjonalne potrzeby obu osób tworzących intymny związek. Ekranowy wizerunek miłości zredukowanej wyłącznie do sfery erotycznej rozkoszy nacechowanej przemocą wpisuje się w tworzenie i umacnianie ideologii hedonistycznej, zniekształcającej pojęcia męskości, kobiecości, miłości, małżeństwa, wierności, płodności ${ }^{49}$.

Lansowanie stereotypu ukazującego związek miłosny jako relację opartą na przemocy pojawiło się także w polskim nieudolnym naśladowaniu trylogii o Greyu, a mianowicie w filmie $365 d n i^{50}$. Prezentacja toksycznego bohatera i karykaturalnego układu polegającego na porwaniu i szantażowaniu kobiety w celu wymuszenia miłości stanowi egzystencjalne kłamstwo fałszujące jej istotną cechę, a mianowicie wolność. Analizowany obraz przewrotnie utożsamił miłość z pożądaniem i spełnieniem fizycznym oraz stanowił egzemplifikację współczesnego zaprzeczenia idei i wartości czystości przedmałżeńskiej oraz wierności.

Erotyzm, nieokiełznaną namiętność i dynamiczną seksualną aktywność młodego pokolenia ukazano wcześniej w obrazie Big $\operatorname{love}^{51}$, a lesbijski związek dziewczyn w filmie Lato mitośc ${ }^{52}$. Sygnalizowane zjawiska polegające na nasyceniu ekranowych narracji coraz większą liczbą scen, sekwencji, motywów skandalicznych może zmierzać w kierunku totalnej liberalizacji odrzucającej całkowicie poszanowanie wszelkich tradycyjnych norm moralnych, obyczajowych i nieliczącej się z wrażliwością widzów.

${ }^{49}$ Cfr. A. Zwoliński, Seksualność w relacjach społecznych, Kraków 2006, 116; D. Rozwadowski, Marksizm kulturowy. 50 lat walki z cywilizacja Zachodu, bmw, bdw, 135.

${ }^{50}$ Cfr. 365 dni, reż. B. Białowąs, T. Mandes, 2020.

${ }^{51}$ Cfr. Big love, reż. B. Białowąs, 2012.

${ }^{52}$ Cfr. Lato miłości, reż. P. Pawlikowski, 2004. 
Shades of Grey ${ }^{46}$, Fifty Shades Darker ${ }^{47}$, and Fifty Shades Freed ${ }^{48}$. The expressive and blunt images of lofty sex significantly distort the ideal of love as a relationship with a significant psychological and spiritual dimension, of mutual devotion, of partnership, of taking into account the desires and emotional needs of both people forming an intimate relationship. The screen image of love reduced only to the erotic sphere of violent pleasure is part of the creation and strengthening of the hedonistic ideology, distorting the concepts of masculinity, femininity, love, marriage, fidelity, and fertility. ${ }^{49}$

The promotion of the stereotype of a love relationship as a relationship based on violence also appeared in the Polish crude, artless imitation of the Grey trilogy, namely in $365 d n i^{50}$. The presentation of a toxic hero and the caricatural system of kidnapping and blackmailing a woman in order to extort love is an existential lie that falsifies its essential feature, which is freedom. The picture perversely equates love with physical desire and fulfilment, and it is an exemplification of the contemporary denial of the idea and value of premarital chastity and fidelity.

Eroticism, unbridled passion and dynamic sexual activity of the young generation were previously shown in Big love ${ }^{51}$, and the lesbian relationship of girls in Lato mitości $i^{52}$. The phenomena signalled by the saturation of screen narratives with an increasing number of scenes, sequences and scandalous motifs may be heading towards total liberalisation that completely rejects respect for all traditional moral and social norms and is absolutely not sensitive to the audience.

${ }^{46}$ Cf. Fifty Shades of Grey, directed by S. Taylor-Johnson, 2015.

${ }^{47}$ Cf. Fifty Shades Darker, directed by J. Foley, 2017.

${ }^{48}$ Cf. Fifty Shades Freed, directed by J. Foley, 2018.

${ }^{49}$ Cf. A. Zwoliński, Seksualność w relacjach społecznych, Kraków 2006, 116; D. Rozwadowski, Marksizm kulturowy. 50 lat walki z cywilizacja Zachodu, bmw, bdw, 135.

${ }^{50}$ Cf. 365 dni, directed by B. Białowąs, T. Mandes, 2020.

${ }^{51}$ Cf. Big love, directed by B. Białowąs, 2012.

52 Cf. Lato miłości, directed by P. Pawlikowski, 2004. 


\section{FASCYNACJA ZLEM}

Przywoływany nierzadko mit medialny głosi, że zło jest ciekawsze i bardziej fascynujące od dobra ${ }^{53}$. Fałszywe założenie utożsamiające spektakularność ze szlachetnością prowadzi do tworzenia obrazów przedstawiających negatywnych postaci: gangsterów (np. Wrogowie publiczni ${ }^{54}$ ), mafiosów (np. Ojciec chrzestny ${ }^{55}$ ), bossów karteli narkotykowych (np. Escobar. Historia nieznana ${ }^{56}$ ), seryjnych morderców (np. Podty, okrutny, zły ${ }^{57}$ ), co czyni z nich bohaterów kultury popularnej. W kinie polskim występuje podobna tendencja nawiązująca do faktów, realiów politycznych, autentycznych wydarzeń i rzeczywistych przestępców, czego przykładem są następujące produkcje: Czerwony pająk ${ }^{58}$, Jestem morderca ${ }^{59}$, Ach śpij kochanie ${ }^{60}$. Specyficznym nurtem współczesnej polskiej kinematografii jest prezentacja służb państwowych zaprzeczająca ich powołaniu i podstawowej misji. Obraz skorumpowanej policji w filmie Drogówka ${ }^{61}$ oraz zdeprawowanego środowiska medycznego w filmie Botoks ${ }^{62}$ poraża skalą społecznego zła i sprzeniewierzenia się profesjonalizmowi, podstawowym normom moralnym oraz zasadom etyki zawodowej.

Oprócz przestępców jako ekranowych bohaterów kultury popularnej pojawiły się obrazy pokazujące prostytutki w konwencji dramatu społeczno-psychologicznego. W produkcjach takich jak np. Sponsoring ${ }^{63}$, Dziennik nimfomanki ${ }^{64}$ dostrzec jednak można

\footnotetext{
${ }^{53}$ Cfr. W. Roszkowski, op. cit., 460.

${ }^{54}$ Cfr. Wrogowie publiczni, reż. M. Mann, 2009.

55 Cfr. Ojciec chrzestny, reż. F.F. Coppola, 1972.

56 Cfr. Escobar. Historia nieznana, reż. A. Di Stefano, 2014.

${ }^{57}$ Cfr. Podty, okrutny, zły, reż. J. Belinger, 2019.

${ }^{58}$ Cfr. Czerwony pająk, reż. M. Koszałka, 2015.

${ }^{59}$ Cfr. Jestem morderca, reż. M. Pieprzyca, 2016.

${ }^{60}$ Cfr. Ach śpij kochanie, reż. K. Lang, 2017.

${ }^{61}$ Cfr. Drogówka, reż. W. Smarzowski, 2013.

${ }^{62}$ Cfr. Botoks, reż. P. Vega, 2017.

${ }^{63}$ Cfr. Sponsoring, reż. M. Szumowska, 2011.

${ }^{64}$ Cfr. Dziennik nimfomanki, reż. C. Molina, 2008.
} 


\section{FASCINATION WITH EVIL}

The media myth, which is often quoted, says that evil is more interesting and fascinating than good. ${ }^{53} \mathrm{~A}$ false assumption equating spectacularity with nobility leads to the creation of images of villains such as gangsters (e.g. Public Enemies ${ }^{54}$ ), mafiosos (e.g. The Godfather ${ }^{55}$ ), bosses of drug cartels (e.g. Escobar. Paradise Lost $^{56}$ ), serial killers (e.g. Extremely Wicked, Shockingly Evil and Vile ${ }^{57}$ ), which makes them heroes of popular culture. Polish cinema similarly tends to refer to facts, political realities, true events and real criminals, as in Czerwony pająk ${ }^{58}$, Jestem morderca ${ }^{59}$, and Ach śpij $k_{\text {ochanie }}{ }^{60}$. A specific trend in modern-day Polish cinematography is the presentation of state institutions as a denial of their vocation and basic mission. The image of the corrupt police in Drogówka ${ }^{61}$ and the depraved medical circles in Botoks ${ }^{62}$ strikes at the scale of social evil and embezzlement of professionalism, basic moral norms and principles of professional ethics.

Apart from the criminals as the screen heroes of popular culture, there are also images showing prostitutes in the convention of a socialpsychological drama. However, in productions such as Sponsoring ${ }^{63}$, Diary of a Nymphomaniac ${ }^{64}$ one can see attempts to present evil as a false good, as well as to perpetuate the ideology of relativism, utilitarianism and hedonism. ${ }^{65}$

${ }^{53}$ Cf. W. Roszkowski, op. cit., 460.

54 Cf. Public Enemies, directed by M. Mann, 2009.

55 Cf. The Godfather, directed by F.F. Coppola, 1972.

56 Cf. Escobar. Paradise Lost, directed by A. Di Stefano, 2014.

57 Cf. Extremely Wicked, Shockingly Evil and Vile, directed by J. Belinger, 2019.

58 Cf. Czerwony pają, directed by M. Koszałka, 2015.

59 Cf. Jestem morderca, directed by M. Pieprzyca, 2016.

60 Cf. Ach śpij kochanie, directed by K. Lang, 2017.

${ }^{61}$ Cf. Drogówka, directed by W. Smarzowski, 2013.

62 Cf. Botoks, directed by P. Vega, 2017.

63 Cf. Sponsoring, directed by M. Szumowska, 2011.

64 Cf. Diary of a Nymphomaniac, directed by C. Molina, 2008.

${ }^{65}$ Cf. W. Roszkowski, op. cit., 459 
próby przedstawiania zła jako fałszywego dobra, a także utrwalania ideologii relatywizmu, utylitaryzmu i hedonizmu ${ }^{65}$.

Koszmarny obraz Kościoła jako instytucji chciwej i zachłannej, co ukazywał film Stugi boże $e^{66}$, a także wizja niemoralnego duchowieństwa pokazana w filmach Stacja Warszawa ${ }^{67}$ i Kler ${ }^{68}$ może być kontynuowana ze względu na coraz większą liczbę ujawnianych skandali obyczajowych i przypadków tuszowania pedofilii księży przez hierarchów. Obrazy stanowiące element propagandy antykatolickiej ukazują wszystkich duchownych jako przestępców oraz pomijają przypomnienie istotnego wymiaru Kościoła jako wspólnoty wiernych i pasterzy ${ }^{69}$, gdzie oprócz grzechu pojawia się również kategoria oraz ideał świętości. Przemilczenie zasług chrześcijaństwa dla światowej kultury i cywilizacji oraz deprecjonowanie jego społecznej roli powoduje obniżenie autorytetu Kościoła i papieża, co wyraziście zostało pokazane w filmie Habemus papam ${ }^{70}$. Kontestacja wszelkich autorytetów to kolejna cecha wspólna zarówno aktualnej cywilizacji, jak i współczesnej kinematografii.

\section{PRZEWIDYWALNE KONTYNUACJE}

Wobec dotychczasowych sukcesów i wieloletniej tradycji trudno przypuszczać, by kino nie kontynuowało realizacji serii wyjątkowo popularnych i lubianych. Najdłuższym fabularnym serialem w dziejach światowej kinematografii jest cykl filmów o Jamesie Bondzie ${ }^{71}$,

${ }^{65}$ Cfr. W. Roszkowski, op. cit., 459

${ }^{66}$ Cfr. Stugi boże, reż. M. Gawryś, 2016.

${ }^{67}$ Cfr. Stacja Warszawa, reż. M. Cuske i in., 2013.

${ }^{68}$ Cfr. Kler, reż. W. Smarzowski, 2018.

${ }^{69} \mathrm{Cfr}$. M. Butkiewicz, Film antyreligijny - propaganda antykościelna $i$ antyklerykalna w kinie XXI w., w: Pokazać niewidzialne. Film religijny w perspektywie teologii środków społecznego przekazu i języka mediów, red. M. Butkiewicz, G. Lęcicki, Warszawa 2019, 98.

${ }^{70}$ Cfr. Habemus papam - mamy papieża, reż. N. Moretti, 2011.

${ }^{71}$ Cfr. K.M. Śmiałkowski, Bond James (postać), w: K.M. Śmiałkowski, Bond. Leksykon, Bielsko-Biała 2009, 42-43. 
The nightmarish image of the Church as a greedy and rapacious institution, as shown in Stugi boże $e^{66}$, as well as the vision of immoral clergy shown in Stacja Warszawa ${ }^{67}$ and Kler ${ }^{68}$ may be continued due to the increasing number of revealed moral scandals and cases of covering up paedophilia of priests by hierarchs. The images that are part of anti-Catholic propaganda show all clergy as criminals and ignore the essential dimension of the Church as a community of believers and shepherds, where besides sin there is also a category and an ideal of holiness. Missing out on the merits of Christianity for world culture and civilisation, and depreciating its social role, undermines the authority of the Church and the Pope, as clearly shown in Habemus papam ${ }^{69}$. The contestation of all kinds of authorities is another common feature of both the current civilisation and contemporary cinematography.

\section{PREDICTABLE CONTINUATION}

In view of its successes and long-standing tradition, it is hard to suppose that the cinema will not continue to produce series that are exceptionally popular and enjoyed. The longest feature series in the history of world cinema is a series about James Bond ${ }^{70}$, British Agent 007, whose adventures have fascinated viewers since 1962. ${ }^{71}$ The last of the 24 official images was produced in $2015 .{ }^{72}$ Due to the coronavirus pandemic, the premiere of the 25 th Bond film has been postponed ${ }^{73}$. The incredible popularity of the most famous British agent and at the same time the most famous spy in the history

${ }^{66}$ Cf. Stugi boże, directed by M. Gawryś, 2016.

${ }^{67}$ Cf. Stacja Warszawa, directed by M. Cuske et al., 2013.

${ }^{68}$ Cf. Kler, directed by W. Smarzowski, 2018.

${ }^{69}$ Cf. Habemus Papam, directed by N. Moretti, 2011.

${ }^{70}$ Cf. K.M. Śmiałkowski, Bond James (postać), in: K.M. Śmiałkowski, Bond. Leksykon, Bielsko-Biała 2009, 42-43.

${ }^{71}$ Cf. Dr. No, directed by T. Young, 1962.

${ }^{72}$ Cf. Spectre, directed by S. Mendes, 2015.

${ }^{73}$ Cf. No Time to Die, directed by C. J. Fukunaga, 2020. 
brytyjskim agencie 007, którego przygody fascynują widzów od $1962 \mathrm{r}^{72}$ Ostatni z 24-ch oficjalnych obrazów został wyprodukowany w 2015 r. $^{73} \mathrm{Z}$ powodu pandemii koronawirusa premierę 25 -go filmu o Bondzie przełożono na późniejszy termin ${ }^{74}$. Niezwykła popularność najsławniejszego brytyjskiego agenta, a zarazem najbardziej znanego szpiega w dziejach światowej kinematografii pozwala mieć nadzieję, że produkcja obrazów prezentujących spektakularne akcje i zadania dzielnego komandora będą zadziwiać oraz zachwycać kolejne pokolenia widzów ${ }^{75}$.

Za wielce prawdopodobne trzeba przyjąć produkowanie kolejnych filmów należących do kosmicznej sagi z cyklu Gwiezdne wojny, której pierwsza część powstała w $1977 \mathrm{r}^{76}$ a ostatnia w 2019 r. ${ }^{77}$ Niełatwo byłoby się pogodzić z zakończeniem serii, która stała się wyjątkowym fenomenem współczesnej kultury popularnej w skali globalnej ${ }^{78}$. Niewykluczone jest również kontynuowanie realizacji następnych filmów o komiksowych superbohaterach Marvela, pokazywanych od 2008 r. $^{79}$ do 2020 r. $^{80}$

Kino dość szybko reagujące na fakty, wydarzenia, przemiany obyczajowe oraz rozmaite zjawiska społeczne podejmie zapewne temat pandemii spowodowanej chorobą covid-19. Obrazy epidemii mają dość bogatą ekranową tradycję nawiązującą zarówno do faktów, jak np. polski film Zaraza ${ }^{81}$, jak i stanowiących podgatunek filmów

${ }^{72}$ Cfr. Doktor No, reż. T. Young, 1962.

73 Cfr. Spectre, reż. S. Mendes, 2015.

${ }^{74}$ Cfr. Nie czas umierać, reż. C. J. Fukunaga, 2020.

75 Cfr. M. Grzesiek, James Bond. Szpieg, którego kochamy. Kulisy najdtuższego serialu w dziejach kina, Wrocław 2011, 565.

${ }^{76}$ Cfr. Gwiezdne wojny. Nowa nadzieja, reż. G. Lucas, 1977.

77 Cfr. Gwiezdne wojny. Skywalker. Odrodzenie, reż. J. J. Abrams, 2019.

${ }^{78}$ Cfr. K. Kaczor, J. Szyłak, Gwiezdne wojny, w: Tenżei in., Kino nowej przygody, Gdańsk 2011, 101- 110; B.J. Jones, George Lucas. Gwiezdne wojny i reszta życia, tł. M. Miłosz, K. Rosłan, A. Wyszogrodzka-Gaik, Warszawa 2016, 437-438.

${ }^{79}$ Cfr. Iron Man, reż. J. Favreau, 2008.

${ }^{80}$ Cfr. Czarna Wdowa, reż. C. Shortland, 2020.

${ }^{81}$ Cfr. Zaraza, reż. R. Załuski, 1971. 
of the world cinematography means that it is to be hoped that the production of pictures presenting spectacular actions and tasks of the brave commander will astonish and delight subsequent generations of viewers ${ }^{74}$.

It is highly probable that more films belonging to the space saga of the series Star Wars will be released, the first part of which was made in $1977^{75}$ and the last part in $2019 .{ }^{76}$ It would not be easy to come to terms with the end of the series, which has become a unique phenomenon of contemporary popular culture on a global scale. ${ }^{77}$ It is also very probable that there will be sequels of the Marvel comic series, shown from $2008{ }^{78}$ to $2020^{79}$

The cinema, which reacts quite quickly to facts, events, moral changes and various social phenomena, will probably take up the topic of the covid-19 pandemic. The images of the epidemic have a fairly rich screen tradition referring to both facts, such as in the Polish movie $\mathrm{Zaraza}^{80}$, and as a sub-genre of catastrophic films ${ }^{81}$. As far as science fiction films are concerned, the production of films about the self-destruction of humanity and the difficult fate of survivors forced to fight for their existence and survival is likely to be continued. ${ }^{82}$

${ }^{74}$ Cf. M. Grzesiek, James Bond. Szpieg, którego kochamy. Kulisy najdtuższego serialu w dziejach kina, Wrocław 2011, 565.

75 Cf. Star Wars Episode IV: A New Hope, directed by G. Lucas, 1977.

${ }^{76}$ Cf. Star Wars: The Rise of Skywalker, directed by J. J. Abrams, 2019.

77 Cf. K. Kaczor, J. Szyłak, Gwiezdne wojny, in: Kino nowej przygody, Gdańsk 2011, 101- 110; B.J. Jones, George Lucas. A Life, New York 2016, 437-438.

${ }^{78}$ Cf. Iron Man, directed by J. Favreau, 2008.

${ }^{79}$ Cf. Black Widow, directed by C. Shortland, 2020.

${ }^{80}$ Cf. Zaraza, directed by R. Załuski, 1971.

${ }^{81}$ Cf. Outbreak, directed by W. Petersen, 1995; Contagion directed by S. Soderbergh, 2011.

${ }^{82}$ Cf. The Road, directed by J. Hillcoat, 2009; Mad Max. Fury Road, directed by G. Miller, 2015. 
katastroficznych ${ }^{82}$. W dziedzinie filmów science fiction kontynuowana pewnie będzie realizacja filmów o autodestrukcji ludzkości i trudnej doli ocalałych zmuszonych do walki o byt i przetrwanie ${ }^{83}$.

Na podstawie przeprowadzonej krytycznej analizy wybranych charakterystycznych współczesnych dzieł kinematograficznych wolno sformułować następujące wnioski dotyczące najbliższej przyszłości kina. Wydaje się, że postępować będzie wulgaryzacja języka filmu, coraz śmielsza erotyzacja obrazów filmowych, odrzucenie klasycznej triady wartości, czyli prawdy, dobra i piękna, podważanie wszelkich autorytetów społecznych: rodziców, nauczycieli, wychowawców, szkoły, państwa, Kościoła, kontestacja tradycji, dziedzictwa duchowego, małżeństwa, rodziny, religii, patriotyzmu, porządku społecznego, hierarchii, wartości pracy ${ }^{84}$. Skandal oraz szokowanie jako elementy przyciągające uwagę w lawinie przekazów medialnych będą wykorzystywane w coraz większym stopniu i w sposób trudny do przewidzenia. Laicyzacja oraz ateizacja będzie wzmacniana poprzez radykalne odrzucenie myślenia o wartościach na rzecz lansowania idei wyboru oraz wolności jako podstawowych norm etycznych i zasad postępowania. Amerykanizacja kultury popularnej zapewne ścierać się będzie ze zjawiskiem globalizacji kinematografii pojmowanej jako dostęp do produkcji pochodzących z różnych krajów.

Nowe modele komunikacji społecznej i rozpowszechniania przekazów medialnych mogą inspirować rozwój nowych form kina jako miejsca oglądania filmów, bądź nowe sposoby ich dystrybucji spowodowane lockdownem wynikającym z sytuacji epidemicznej.

${ }^{82}$ Cfr. Epidemia, reż. W. Petersen, 1995; Contagion. Epidemia strachu, reż. S. Soderbergh, 2011.

${ }^{83}$ Cfr. Droga, reż. J. Hillcoat, 2009; Mad Max. Na drodze gniewu, reż. G. Miller, 2015.

${ }^{84}$ Cfr. M. Bock-Côté, Multikulturalizm jako religia polityczna, tł. M. Chojnacki, Warszawa 2017, 92. 


\section{$* * *$}

On the basis of a critical analysis of selected characteristic works of contemporary cinematography, the following conclusions can be drawn concerning the immediate future of cinema. It seems that the vulgarisation of the language of film, the increasingly bold eroticisation of film images, the rejection of the classical triad of values, i.e. truth, goodness and beauty, the undermining of all social authorities including parents, teachers, educators, school, state, and the Church, the contestation of tradition, spiritual heritage, marriage, family, religion, patriotism, social order, hierarchy and the value of work, all seem to be progressing. ${ }^{83}$ Scandal and shock as attentiongrabbing elements in an avalanche of media messages will be increasingly used in a way that is difficult to predict. Laissez-faire and atheism will be reinforced by a radical rejection of value-based thinking in favour of promoting the idea of choice and freedom as fundamental ethical norms and rules of conduct. The Americanisation of popular culture will probably clash with the phenomenon of the globalisation of cinematography, understood as access to productions from different countries.

New models of social communication and media distribution can inspire the development of new forms of cinema as a place to watch movies, or new ways of distributing them due to the lockdown resulting from the epidemic.

Scientific research and artistic creation is largely unpredictable. It is hard to suppose that in the cinematography of the third decade of the 21st century there will be some radical ideological turn, similar to the Copernican Revolution. However, since Star Wars triggered a real revolution in the popularity and perception of cinematographic art, one can only hope for the emergence of new talents that will match those of the old masters and create epochal masterpieces. Whether,

${ }^{83}$ Cf. M. Bock-Côté, Multiculturalism as a political religion, In Le Débat Volume 186, Issue 4, 2015, pages 122 to 136, Polish translation by M. Chojnacki, Warsaw 2017, 92. 
Poszukiwania naukowe oraz twórczość artystyczna jest w dużym stopniu nieprzewidywalna. Trudno przypuszczać, że w kinematografii trzeciej dekady XXI w. nastąpi jakiś radykalny zwrot ideowy na podobieństwo przewrotu kopernikańskiego. Skoro jednak Gwiezdne wojny spowodowały istną rewolucję $\mathrm{w}$ dziedzinie popularności i percepcji sztuki kinematograficznej, to wolno mieć nadzieję na pojawienie się nowych talentów dorównujących dawnym mistrzom i tworzących dzieła epokowe. Czy w zakresie idei będą zdolne przeciwstawić się współczesnemu światopoglądowi kontestacji, dyktatowi różnorodności - czas pokaże.

\section{Podsumowanie}

Syntetyczna prezentacja zasadniczych cech współczesnej kinematografii, kontestująca klasyczną triadę wartości: prawdy, dobra i piękna. Przedstawienie głównych nurtów współczesnej kinematografii na przykładzie filmów zagranicznych i polskich. Omówienie takich zjawisk jak wulgaryzacja, erotyzacja, tolerancja. Próba przewidzenia głównych kierunków ideologicznych kina trzeciej dekady XXI wieku.

Słowa kluczowe: Nowe idee, kino, wulgaryzacja, erotyzacja, kontestacja, tolerancja

\section{Nota 0 autorze}

Grzegorz Łęcicki, prof. UKSW dr hab., apologetyk, teolog kultury i mediów, kierownik Katedry Teologii Środków Społecznego Przekazu i Edukacji Medialnej, w latach 2018-2020 dyrektor Instytutu Edukacji Medialnej i Dziennikarstwa na Wydziale Teologicznym UKSW; badacz mediów audiowizualnych, głównie filmów fabularnych oraz seriali telewizyjnych.

\section{Bibliografia}

Bock-Côté M., Multikulturalizm jako religia polityczna, tł. M. Chojnacki, Warszawa 2017.

Butkiewicz M., Film antyreligijny - propaganda antykościelna i antyklerykalna w kinie XXI w., w: Pokazać niewidzialne. Film religijny w perspektywie teologii 
in terms of ideas, they will be able to oppose the contemporary worldview of contestation and the dictate of diversity, the time will tell.

\section{Summary}

A synthetic presentation of the essential features of contemporary cinematography, contesting the classical triad of values: truth, goodness and beauty. Presenting the main trends of the current cinematography on the basis of examples of foreign and Polish films. Discussion of such phenomena as vulgarization, eroticization, tolerance. An attempt to predict the main ideological directions of cinema in the third decade of the 21 st century.

Key words: New ideas, cinema, vulgarization, eroticisation, contestation, tolerance

\section{About the Author}

Grzegorz Łęcicki, Ph.D, Professor at the UKSW, an apologist, cultural and media theologian, Head of the Department of Theology of Social Media Communications and Media Education, between 2018 and 2020 Director of the Institute of Media Education and Journalism at the Theological Faculty of the UKSW; a researcher in audiovisual media, mainly feature films and TV series.

\section{Bibliography}

Bock-Côté M., Multiculturalism as a political religion, In Le Débat Volume 186, Issue 4, 2015, pages 122 to 136; Polish translation by M. Chojnacki, Warsaw 2017.

Butkiewicz M., Film antyreligijny - propaganda antykościelna i antyklerykalna w kinie XXI w., in: Pokazać niewidzialne. Film religijny w perspektywie teologii środków społecznego przekazu i języka mediów, ed. M. Butkiewicz, G. Łęcicki, Warsaw 2019.

Grzesiek M., James Bond. Szpieg, którego kochamy. Kulisy najdłuższego serialu w dziejach kina, Wrocław 2011.

Hendrykowski M., Język filmu, in: Słownik terminów filmowych, Poznań 1994.

Jones B. J., George Lucas. A Life, New York 2016. 
środków społecznego przekazu i języka mediów, red. M. Butkiewicz, G. Łęcicki, Warszawa 2019.

Grzesiek M., James Bond. Szpieg, którego kochamy. Kulisy najdłuższego serialu w dziejach kina, Wrocław 2011.

Hendrykowski M., Język filmu, w: Tenże, Stownik terminów filmowych, Poznań 1994.

Jones B. J., George Lucas. Gwiezdne wojny i reszta życia, tł. M. Miłosz, K. Rosłan, A. Wyszogrodzka-Gaik, Warszawa 2016.

Koźlenko D., Sami swoi. Za kulisami komedii wszech czasów, Warszawa 2016.

Kumaniecki K., Słownik tacińsko-polski, Warszawa 1999.

Łęcicki G., Media audiowizualne w nauczaniu Jana Pawła II, Warszawa 2013.

Łuczak M., Miś czyli świat wedlug Barei, Warszawa bdw.

Piotrowski P. K., 07 zgłasza się. Opowieść o serialu, Warszawa 2013.

Płażewski J., Historia filmu francuskiego, Warszawa 2005.

Płażewski J., Język filmu, Warszawa 2008.

Popularna encyklopedia mass mediów, red. J. Skrzypczak Poznań 1999.

Replewicz M., Oczko się odlepiło temu misiu... Biografia Stanisława Barei, Warszawa 2015.

Replewicz M., Stanisław Bareja alternatywnie, Poznań 2019.

Roszkowski W., Roztrzaskane lustro. Upadek cywilizacji zachodniej, Kraków 2019.

Rozwadowski D., Marksizm kulturowy. 50 lat walki z cywilizacja Zachodu, bmw, bdw.

Sharp J., Za różowa kurtyną. Historia japońskiego kina erotycznego, tł. J. Murczyńska, K. Klimek, G. Żuchowska, Warszawa - Kraków 2011.

Szyłak J. i in., Kino nowej przygody, Gdańsk 2011.

Śmiałkowski K. M., Bond. Leksykon, Bielsko-Biała 2009.

Zwoliński A., Obraz w relacjach społecznych, Kraków 2004.

Zwoliński A., Seksualność w relacjach spolecznych, Kraków 2006.

Zwoliński A., Stowo w relacjach społecznych, Kraków 2003.

Filmografia

07 zgłoś się, reż. K. Szmagier i in., 1979-1987.

$365 d n i$, reż. B. Białowąs, T. Mandes, 2020.

Ach śpij kochanie, reż. K. Lang, 2017.

Bad boy, reż. P. Vega, 2020.

Big love, reż. B. Białowąs, 2012.

Botoks, reż. P. Vega, 2017.

Contagion. Epidemia strachu, reż. S. Soderbergh, 2011. 
Koźlenko D., Sami swoi. Za kulisami komedii wszech czasów, Warsaw 2016. Kumaniecki K., Stownik tacińsko-polski, Warsaw 1999.

Łęcicki G., Media audiowizualne w nauczaniu Jana Pawła II, Warsaw 2013.

Łuczak M., Miś czyli świat według Barei, Warsaw bdw.

Piotrowski P. K., 07 zgłasza się. Opowieść o serialu, Warsaw 2013.

Płażewski J., Historia filmu francuskiego, Warsaw 2005.

Płażewski J., Język filmu, Warsaw 2008.

Popularna encyklopedia mass mediów, ed. J. Skrzypczak Poznań 1999.

Replewicz M., Oczko się odlepito temu misiu... Biografia Stanisława Barei, Warsaw 2015.

Replewicz M., Stanisław Bareja alternatywnie, Poznań 2019.

Roszkowski W., Roztrzaskane lustro. Upadek cywilizacji zachodniej, Kraków 2019.

Rozwadowski D., Marksizm kulturowy. 50 lat walki z cywilizacja Zachodu, bmw, bdw.

Sharp J., Behind the Pink Curtain: The Complete History of Japanese Sex Cinema, Polish translation by J. Murczyńska, K. Klimek, G. Żuchowska, Warsaw Kraków 2011.

Szyłak J. et al., Kino nowej przygody, Gdańsk 2011.

Śmiałkowski K. M., Bond. Leksykon, Bielsko-Biała 2009.

Zwoliński A., Obraz w relacjach społecznych, Kraków 2004.

Zwoliński A., Seksualność w relacjach społecznych, Kraków 2006.

Zwoliński A., Słowo w relacjach społecznych, Kraków 2003.

Filmografia

07 zgłoś się, directed by K. Szmagier i in., 1979-1987.

365 dni, directed by B. Białowąs, T. Mandes, 2020.

Ach śpij kochanie, directed by K. Lang, 2017.

Bad boy, directed by P. Vega, 2020.

Big love, directed by B. Białowąs, 2012.

Black Widow, directed by C. Shortland, 2020.

Blue Is The Warmest Colour, directed by A. Kechiche, 2013.

Botoks, directed by P. Vega, 2017.

Brokeback Mountain, directed by A. Lee, 2005.

Contagion, directed by S. Soderbergh, 2011.

Czerwony pająk, directed by M. Koszałka, 2015.

Diary of a Nymphomaniac, directed by C. Molina, 2008.

Dr. No, directed by T. Young, 1962.

Drogówka, directed by W. Smarzowski, 2013. 
Czarna Wdowa, reż. C. Shortland, 2020.

Czerwony pająk, reż. M. Koszałka, 2015.

Doktor No, reż. T. Young, 1962.

Droga, reż. J. Hillcoat, 2009.

Drogówka, reż. W. Smarzowski, 2013.

Dziennik nimfomanki, reż. C. Molina, 2008.

Dziewięć i pót tygodnia, reż. A. Lyne, 1986.

Emmanuelle, reż. J. Jaeckin, 1974.

Epidemia, reż. W. Petersen, 1995.

Escobar. Historia nieznana, reż. A. Di Stefano, 2014.

Flower and snake, reż. M. Konuma, 1974.

Futro z misia, reż. K. Anuszewski, M. Milowicz, 2019.

Gwiezdne wojny. Nowa nadzieja, reż. G. Lucas, 1977.

Gwiezdne wojny. Skywalker. Odrodzenie, reż. J. J. Abrams, 2019.

Habemus papam - mamy papieża , reż. N. Moretti, 2011.

Historia O, reż. . J. Jaeckin, 1975.

Idealny chłopak dla mojej dziewczyny, reż. T. Konecki, 2009.

Iron Man, reż. J. Favreau, 2008.

Ja teraz kłamię, reż. P. Borowski, 2019.

Jestem morderca, reż. M. Pieprzyca, 2016.

Kler, reż. W. Smarzowski, 2018.

Kobiety mafii, reż. P. Vega, 2018.

Kobiety mafii 2, reż. P. Vega, 2019.

Kochaj albo rzuć, reż. S. Chęciński, 1977.

Lato miłości, reż. P. Pawlikowski, 2004.

Lejdis, reż. T. Konecki, 2008.

Listy do M, reż. M. Okorn, 2011.

Lolita, reż. A. Lyne, 1997.

Mad Max. Na drodze gniewu, reż. G. Miller, 2015.

Mała wielka miłość, reż. Ł. Karwowski, 2008.

Mandragora, reż. W. Grodecki, 1997.

Mayday, reż. S. Akina, 2019.

Misz masz czyli kogel mogel 3, reż. K. Piwowarski, 2019.

Miś, reż. S. Bareja, 1980.

Moje własne Idaho, reż. G. Van Sant, 1991.

Nie czas umierać, reż. C. J. Fukunaga, 2020.

Nie ma mocnych, reż. S. Chęciński, 1974.

(Nie)znajomi, reż. T. Śliwa, 2019. 
Emmanuelle, directed by J. Jaeckin, 1974.

Escobar. Paradise Lost, directed by A. Di Stefano, 2014.

Flower and Snake, directed by M. Konuma, 1974.

Futro z misia, directed by K. Anuszewski, M. Milowicz, 2019.

Habemus papam, directed by N. Moretti, 2011.

Idealny chłopak dla mojej dziewczyny, directed by T. Konecki, 2009.

Iron Man, directed by J. Favreau, 2008.

Ja teraz kłamie, directed by P. Borowski, 2019.

Jestem morderca, directed by M. Pieprzyca, 2016.

Kler, directed by W. Smarzowski, 2018.

Kobiety mafii, directed by P. Vega, 2018.

Kobiety mafii 2, directed by P. Vega, 2019.

Kochaj albo rzuć [translated as Love or Leave], directed by S. Chęciński, 1977.

Lato miłości, directed by P. Pawlikowski, 2004.

Lejdis, directed by T. Konecki, 2008.

Listy do M, directed by M. Okorn, 2011.

Lolita, directed by A. Lyne, 1997.

Mad Max. Fury Road, directed by G. Miller, 2015.

Mała wielka miłość, directed by Ł. Karwowski, 2008.

Mandragora, directed by W. Grodecki, 1997.

Mayday, directed by S. Akina, 2019.

Misz masz czyli kogel mogel 3, directed by K. Piwowarski, 2019.

Miś [translated as Teady Bear], directed by S. Bareja, 1980.

My Own Private Idaho, directed by G. Van Sant, 1991.

Nie ma mocnych [translated as Take It Easy], directed by S. Chęciński, 1974.

(Nie)znajomi, directed by T. Śliwa, 2019.

Nina, directed by O. Chajdas, 2018.

Nine 1/2 Weeks, directed by A. Lyne, 1986.

No Time to Die, directed by C. J. Fukunaga, 2020.

Outbreak, directed by W. Petersen, 1995.

Pitbull. Nowe porzadki, directed by P. Vega, 2016.

Plan B, directed by K. Dębska, 2018.

Planeta singli 3, directed by S. Akina, M. Chaciński, 2019.

Polityka, directed by P. Vega, 2019.

Public Enemies, directed by M. Mann, 2009.

Rope cosmetology, directed by S. Nishimura, 1978.

Sami swoi [translated as All Friends Here or Our Folks], directed by S. Chęciński, 1967. 
Nina, reż. O. Chajdas, 2018.

Obraz, reż. R. Metzger, 1975.

Ojciec chrzestny, reż. F.F. Coppola, 1972.

Pitbull. Nowe porządki, reż. P. Vega, 2016.

Plan B, reż. K. Dębska, 2018.

Planeta singli 3, reż. S. Akina, M. Chaciński, 2019.

Polityka, reż. P. Vega, 2019.

Rope cosmetology, reż. S. Nishimura, 1978.

Sami swoi, reż. S. Chęciński, 1967.

Sekretarka, reż. S. Shainberg, 2002.

Seksmisja, reż. J. Machulski, 1983.

Stugi boże, reż. M. Gawryś, 2016.

Spectre, reż. S. Mendes, 2015.

Sponsoring, reż. M. Szumowska, 2011.

Stacja Warszawa, reż. M. Cuske i in., 2013.

Tajemnice Brokeback Mountain, reż. A. Lee, 2005.

Wilk z Wall Street, reż. M. Scorsese, 2013.

Wimię..., reż. M. Szumowska, 2013.

Wrogowie publiczni, reż. M. Mann, 2009.

Zaraza, reż. R. Załuski, 1971.

Życie Adeli, reż. A. Kechiche, 2013. 
Secretary, directed by S. Shainberg, 2002.

Seksmisja [translated as Sexmission], directed by J. Machulski, 1983.

Stugi boże, directed by M. Gawryś, 2016.

Spectre, directed by S. Mendes, 2015.

Sponsoring, directed by M. Szumowska, 2011.

Stacja Warszawa, directed by M. Cuske et. al. 2013.

Star Wars Episode IV: A New Hope, directed by G. Lucas, 1977.

Star Wars: The Rise of Skywalker, directed by J. J. Abrams, 2019.

Story of $O$, directed by J. Jaeckin, 1975.

The Godfather, directed by F.F. Coppola, 1972.

The Image, directed by R. Metzger, 1975.

The Road, directed by J. Hillcoat, 2009.

The Wolf of Wall Street, directed by M. Scorsese, 2013.

W imię..., directed by M. Szumowska, 2013.

Zaraza, directed by R. Załuski, 1971. 